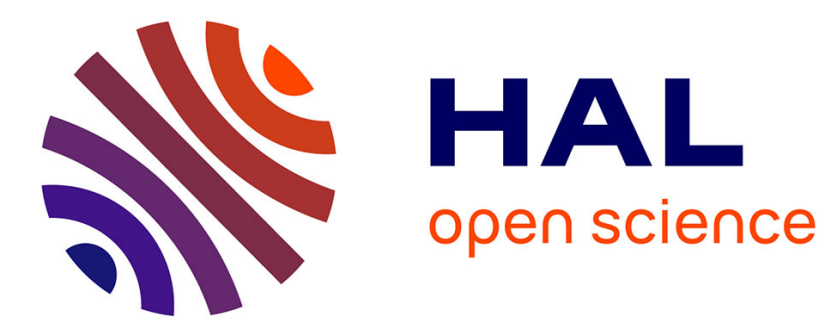

\title{
Bulk Li mobility enhancement in Spark Plasma Sintered Li(7-3x)AlxLa3Zr2O12 garnet
}

Adriana Castillo, Thibault Charpentier, Olivier Rapaud, Nicolas Pradeilles, Saïd Yagoubi, Eddy Foy, Mélanie Moskura, Hicham Khodja

\section{To cite this version:}

Adriana Castillo, Thibault Charpentier, Olivier Rapaud, Nicolas Pradeilles, Saïd Yagoubi, et al.. Bulk Li mobility enhancement in Spark Plasma Sintered Li(7-3x)AlxLa3Zr2O12 garnet. Ceramics International, 2018, 44, pp.18844-18850. 10.1016/j.ceramint.2018.07.119 . cea-01855322

HAL Id: cea-01855322

https://hal-cea.archives-ouvertes.fr/cea-01855322

Submitted on 7 Aug 2018

HAL is a multi-disciplinary open access archive for the deposit and dissemination of scientific research documents, whether they are published or not. The documents may come from teaching and research institutions in France or abroad, or from public or private research centers.
L'archive ouverte pluridisciplinaire HAL, est destinée au dépôt et à la diffusion de documents scientifiques de niveau recherche, publiés ou non, émanant des établissements d'enseignement et de recherche français ou étrangers, des laboratoires publics ou privés. 


\title{
Bulk Li mobility enhancement in Spark Plasma Sintered $\mathrm{Li}_{(7-3 \mathrm{x})} \mathrm{Al}_{\mathrm{x}} \mathrm{La}_{3} \mathrm{Zr}_{2} \mathrm{O}_{12}$ garnet
}

\author{
Adriana Castillo ${ }^{1}$, Thibault Charpentier ${ }^{1}$, Olivier Rapaud ${ }^{2}$, Nicolas Pradeilles ${ }^{2}$, Saïd Yagoubi ${ }^{1}$, \\ Eddy Foy ${ }^{1}$, Mélanie Moskura ${ }^{1}$, Hicham Khodja ${ }^{1}$ \\ ${ }^{1}$ NIMBE, CEA, CNRS, Université Paris-Saclay, CEA Saclay, 91191 Gif sur Yvette Cedex, \\ France \\ ${ }^{2}$ IRCER, UMR CNRS 7315, 12 rue Atlantis, 87068 Limoges Cedex, France
}

\begin{abstract}
$\mathrm{Li}_{(7-3 \mathrm{x})} \mathrm{Al}_{\mathrm{x}} \mathrm{La}_{3} \mathrm{Zr}_{2} \mathrm{O}_{12}$ (LLAZO) Al-doped garnets display high ionic conductivity in the range of $\sim 10^{-4}{\mathrm{~S} . \mathrm{cm}^{-1}}$ at room temperature and are thus envisioned for future solid-state batteries. In this study, LLAZO powders with two doping levels were synthetized using a solid-state route and sintered using Spark Plasma Sintering (SPS). Both pristine and SPS crushed pellet powders were investigated using X-Ray Diffraction (XRD) confirming the formation of the most conducting cubic phase. Ionic conductivity measurements were performed using electrochemical impedance spectroscopy. $\mathrm{Li}$ and $\mathrm{Al}$ distributions among available sites were identified using Magic Angle Spinning (MAS) Nuclear Magnetic Resonance (NMR) experiments, and Li mobility was explored using ${ }^{7} \mathrm{Li}$ static wideline NMR spectroscopy. Results show that SPS treatment, beyond producing highly densified pellets, mainly modifies Al distribution and strongly impacts the bulk $\mathrm{Li}^{+}$mobility.
\end{abstract}

Keywords: Al-doped garnet; NMR; bulk $\mathrm{Li}^{+}$mobility; Li dynamics. 


\section{Introduction}

Al-doped garnets $\mathrm{Li}_{(7-3 \mathrm{x})} \mathrm{Al}_{\mathrm{x}} \mathrm{La}_{3} \mathrm{Zr}_{2} \mathrm{O}_{12}$ are characterized by a high ionic conductivity in the

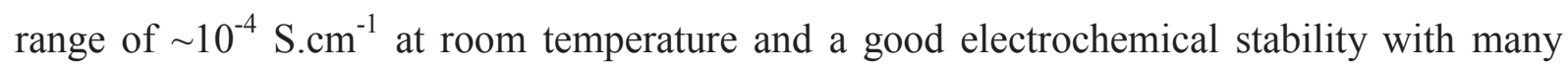
electrode materials $[1,2]$. They are therefore envisioned as promising electrolyte material for all-solid-state batteries. By introducing more vacancies in the Li sublattice, aliovalent $\mathrm{Al}^{3+}$ doping helps stabilize the more conducting cubic polymorph $(I a-3 d)$ at room temperature compared to the tetragonal polymorph (I $\left.4_{1} / a c d\right)$ of $\mathrm{Li}_{7} \mathrm{La}_{3} \mathrm{Zr}_{2} \mathrm{O}_{12}$ (LLZO) [1, 3- 5].

Within the cubic LLZO structure, $\mathrm{Li}^{+}$ions occupy the $24 \mathrm{~d}$ tetrahedral sites and $48 \mathrm{~g} / 96 \mathrm{~h}$ octahedral sites which are connected with each other by face sharing (see Fig. 1) [1, 6]. Due to partial occupancy of identified Li sites, the diffusion of $\mathrm{Li}^{+}$occurs by a concerted migration mechanism $[4,7,8]$, and the Li content and its distribution among $24 \mathrm{~d}$ and 48g/96h sites affects the activation energy of the diffusion process [9].

DFT calculations have shown that the most energetically favorable locations of $\mathrm{Al}^{3+}$ dopant in the cubic LLAZO structure are the two $24 \mathrm{~d}$ and $48 \mathrm{~g} / 96 \mathrm{~h}$ Li sites [10]. Therefore, one may wonder how $\mathrm{Al}^{3+}$ substitution at $\mathrm{Li}$ sites can impact the diffusion pathways of $\mathrm{Li}^{+}$and its mobility.

Several studies have used NMR spectroscopy to investigate Li structural environment and dynamics in tetragonal LLZO [11] and Al-doped (0.9 wt.\% and 1.1 wt.\%) cubic LLAZO [12, 13]. Site occupancies in the prepared LLAZO were identified using ${ }^{27} \mathrm{Al}$ and ${ }^{6} \mathrm{Li}$ MAS NMR [1, 14-16]. NMR relaxation time measurements allowed getting Li dynamics parameters, namely the Li mean jump rate and activation energy [11, 12]. Microscopic Li dynamics deduced from NMR experiments were also compared with ionic conductivity measurements. The latter, obtained by impedance spectroscopy, reflect Li dynamics only at a macro-scale, 
but both methods were found to be in good agreement [11]. However in the studies mentioned above, the occupancy of sites was not correlated with Li dynamics.

Dense pellets are required to increase the ionic conductivity as the detrimental effect of porosity is minimized. Among sintering methods, Spark Plasma Sintering is a very efficient technique to sinter garnets as it produces high density pellets $(>95 \%$ of the theoretical density) in a short time $(<10 \mathrm{~min})$, avoiding further material degradation reactions at high temperature and grain growth $[17,18]$.

In this work, we have studied for two Al-doped garnet powders how SPS treatment modifies Li and Al sites occupancies. Using NMR techniques and impedance spectroscopy measurements we also determined to what extend it impacts the Li dynamics.

\section{Sample preparation}

\subsection{Powder synthesis}

LLAZO powders were prepared by conventional solid-state method using $\mathrm{Li}_{2} \mathrm{CO}_{3}(99.997 \%$, Aldrich), $\mathrm{Al}_{2} \mathrm{O}_{3}$ (99.998\%, Aldrich), $\mathrm{ZrO}_{2}$ (99.978\%, Alfa) and $\mathrm{La}_{2} \mathrm{O}_{3}$ (99.999\%, Aldrich) precursors. A $15 \% \mathrm{Li}_{2} \mathrm{CO}_{3}$ excess was added to compensate for $\mathrm{Li}$ volatilization at high temperature. $\mathrm{Al}_{2} \mathrm{O}_{3}, \mathrm{La}_{2} \mathrm{O}_{3}$ and $\mathrm{ZrO}_{2}$ were dried at $900{ }^{\circ} \mathrm{C}$ for $12 \mathrm{~h}$ and $\mathrm{Li}_{2} \mathrm{CO}_{3}$ at $120{ }^{\circ} \mathrm{C}$ before weighing. Each mixture was initially calcined at $450{ }^{\circ} \mathrm{C}$ in molybdenum crucible, milled using a planetary ball-miller with agate balls in an agate bowl for 4 hours, then transferred in alumina crucible for a treatment at $800{ }^{\circ} \mathrm{C}$ overnight. A second ball-milling process was applied with similar conditions before a final calcination at $900{ }^{\circ} \mathrm{C}$ during 50 hours under dry air to obtain the pure cubic garnet phase, free from $\mathrm{La}_{2} \mathrm{Zr}_{2} \mathrm{O}_{7}$ intermediate phase. Two powders with different Al content were prepared, the expected Li:Al:La:Zr molar ratios were 54.51:2.08:26.04:17.36 and 51.65:3.04:26.04:17.36 (thereafter referred as S1 and S2 respectively). 


\subsection{SPS sintering}

Powders were sintered without any additives using a Spark Plasma Sintering apparatus (Fuji Syntex, Dr Sinter 825, Japan) under dynamic vacuum. The powders were poured into a graphite die with an inner diameter of $16.4 \mathrm{~mm}$. A compressive graphite foil $(0.2 \mathrm{~mm}$ thick, Papyex $(\mathbb{C}$, Mersen Goup, France) was used as lubricant to coat the inner surface of the die and the surface of the punches. The powders were heated under vacuum up to $1050{ }^{\circ} \mathrm{C}$ for 10 minutes with a heating rate of $100{ }^{\circ} \mathrm{C} / \mathrm{min}$. A uniaxial pressure of $75 \mathrm{MPa}$ was applied upon heating. Cooling rate was $50{ }^{\circ} \mathrm{C} / \mathrm{min}$. Two pellets were produced based on the $\mathrm{S} 1$ and $\mathrm{S} 2$ powders, named S1-SPS and S2-SPS. The pellets were slightly polished to remove Papyex and possible $\mathrm{La}_{2} \mathrm{Zr}_{2} \mathrm{O}_{7}$ impurity. The latter can form during the sintering process at the interface between the graphitic sheet and the powder due to the high reactivity between lithium and carbon at high temperature inducing $\mathrm{Li}_{2} \mathrm{CO}_{3}$ formation and consequently leading to a loss of Li from the garnet structure $[19,20]$.

The pellets density was determined by weighing the pellets on a microbalance and measuring the pellets dimensions with a caliper.

To avoid moisture and $\mathrm{CO}_{2}$ exposure, all powders and pellets were stored in an Ar-filled glovebox, and air exposure was limited as much as possible.

\subsection{Characterization methods}

$\mathrm{Li}, \mathrm{Al}, \mathrm{La}$ and $\mathrm{Zr}$ concentrations in powders and pellets were measured by Inductive Coupled Plasma (ICP) Optical Emission Spectroscopy (OES) (Varian VistaPro spectrometer).

The structural characterization of the powders and sintered samples was performed by X-ray powder diffraction (XRD) using a Bruker AXS D8 Advance diffractometer equipped with a Lynxeye XE-T linear detector $\left(\mathrm{Cu}-\mathrm{K}_{\alpha 1,2}\right.$ radiations) in the Bragg-Brentano configuration. The patterns were acquired at room temperature with $2 \theta$ ranging from $10^{\circ}$ to $120^{\circ}\left(5 \mathrm{~s}-0.01^{\circ}\right.$ 
steps). The JANA2006 software [29] was used for structural refinement of the powder X-ray data. The profile was described by a pseudo-Voigt function and a polynomial background was refined in addition to the manual one. Berar-Baldinozzi method was used for the peak shape asymmetry.

The microstructure of the pellets was observed using Scanning Electron Microscopy (JEOL JSM-7001F) with an acceleration voltage of $15 \mathrm{kV}$.

Electrochemical Impedance Spectroscopy (EIS) measurements were carried out using a BioLogic MTZ-35 on polished and gold sputtered pellets in the frequency range of $1 \mathrm{~Hz}-10 \mathrm{MHz}$ under Ar atmosphere and at temperatures ranging from room temperature to $227^{\circ} \mathrm{C}$.

${ }^{6} \mathrm{Li}$ and ${ }^{27} \mathrm{Al}$ solid-state MAS NMR spectra were collected on a Bruker AVANCE II solidstate NMR spectrometer operating at a magnetic field of $11.72 \mathrm{~T}$ (500WB) using $4 \mathrm{~mm}$ rotors and a Bruker probe at a sample spinning frequency of $12.5 \mathrm{kHz}$. Larmor frequencies of ${ }^{6} \mathrm{Li}$ and ${ }^{27} \mathrm{Al}$ were $73.47 \mathrm{MHz}$ and $130.08 \mathrm{MHz}$, respectively. Chemical shifts were referenced against external aqueous solutions of $1 \mathrm{M} \mathrm{AlCl} 3(0 \mathrm{ppm})$ and $1 \mathrm{M} \mathrm{LiCl}(0 \mathrm{ppm})$. For ${ }^{6} \mathrm{Li}$, additional data were collected at a higher magnetic field of $20 \mathrm{~T}$ (850WB) to obtain a better resolution at $10 \mathrm{kHz}$ spinning frequency.

${ }^{27} \mathrm{Al}(\mathrm{I}=5 / 2)$ MAS NMR spectra were acquired using a single short pulse excitation $(1 \mu \mathrm{s}$, tip angle of $\sim 15^{\circ}$ ) to ensure quantitativeness (i.e., working in the non-selective linear regime at short pulse length for quadrupolar nuclei). For ${ }^{6} \mathrm{Li}(\mathrm{I}=1)$, due to the very long nuclear spinlattice relaxation time, a pre-saturation period followed by a recovery delay ( $200 \mathrm{~s})$ was systematically employed before a single pulse excitation.

For Li dynamics investigation, ${ }^{7} \mathrm{Li}(\mathrm{I}=3 / 2)$ wideline (i.e., non-spinning) NMR spectra and nuclear relaxation measurements were acquired at a Larmor frequency of $116.4 \mathrm{MHz}$ on a 
Bruker AVANCE I spectrometer operating at a magnetic field of $7.02 \mathrm{~T}$ (300WB) using a variable temperature wideline probe in the $-123{ }^{\circ} \mathrm{C}-227^{\circ} \mathrm{C}$ range. For lower temperatures (down to $-183{ }^{\circ} \mathrm{C}$ ), data were collected using an Oxford Spectrostat NMR system cooled with liquid nitrogen.

\section{Results and discussion}

\subsection{Structural arrangement and evolution after SPS treatment}

S1, S2, and crushed S1-SPS and S2-SPS powders were investigated by XRD in order to confirm the cubic phase formation and to identify possible modifications after SPS treatment.

The XRD patterns of the two pristine samples S1 and S2 are unambiguously indexed with the garnet cubic phase (Ia-3d) (ICSD \#238688) as shown in Fig. 2.

As $\mathrm{Al}^{3+}$ ionic radius is smaller than $\mathrm{Li}^{+}(39 \mathrm{pm}$ vs. $59 \mathrm{pm})$ a lattice parameter decrease is expected with increasing the doping level. From le Bail refinements (see example in Fig. S1), we found a smaller lattice parameter for S2 (12.9870(6) $\AA$ ) compared to S1 (13.0124(4) $\AA$ ) confirming the unit cell shrinkage and its correlation with the $\mathrm{Al}^{3+}$ content. In the two pristine samples $\mathrm{S} 1$ and $\mathrm{S} 2, \mathrm{LaAlO}_{3}$ impurity was found in XRD patterns and confirmed by ${ }^{27} \mathrm{~A} 1 \mathrm{MAS}$ NMR (see below). Moreover we suspected the existence of a second impurity $\mathrm{Li}_{1.82} \mathrm{ZrO}_{3}$ (ICSD \#35236) on the pristine samples, which main reflection (021) is observed around $26.76^{\circ}$. However, we noticed the disappearance of impurity reflections after the SPS treatment and no modification of the LLAZO cubic phase as illustrated on Fig. 2. Moreover a decrease in the unit cell parameters was observed in the SPS sintered samples (Table S1) compared to the pristine powders (13.0124 $\AA$ and $12.9758 \AA$ for S1 and S1-SPS, $12.9870 \AA$ and $12.9634 \AA$ for S2 and S2-SPS). This suggests that the removal of $\mathrm{LaAlO}_{3}$ after sintering could result from the insertion of further $\mathrm{Al}$ ions in the garnet structure. 


\subsection{Elemental compositions and microstructures of powders and pellets}

Elemental compositions from ICP-OES analyses are reported in Table 1. As oxygen concentration cannot be measured by ICP analysis, results are expressed as the ratio of elemental concentrations normalized to the sum of $\mathrm{Li}, \mathrm{Al}, \mathrm{Zr}$ and $\mathrm{La}$ concentrations. Importantly, concentrations in the garnet phase were deduced after removal of the $\mathrm{LaAlO}_{3}$ parasitic phase contribution, estimated from ${ }^{27} \mathrm{Al}$ MAS NMR as explained in section 3.3. With SPS treatment, $\mathrm{Al}$ content has increased in the two pellets as suggested by XRD analysis.

In Figure 3 we show backscattered SEM images of S1 and S2 powders and front views of S1SPS and S2-SPS polished pellets. Grain sizes range from 2 to $10 \mu \mathrm{m}$ and the two pellets seem well sintered with little porosity. The measured relative densities of SPS-sintered pellets are

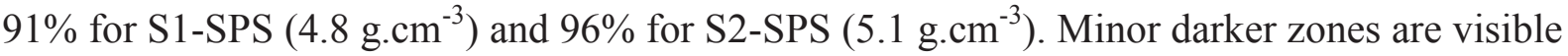
on the SEM images indicating the existence of a lighter phase as $\mathrm{LaAlO}_{3}$ impurity.

\subsection{Ionic conductivity}

The ionic conductivities of the two sintered pellets were measured by EIS. An example of the Nyquist diagram obtained at $44{ }^{\circ} \mathrm{C}$ for S1-SPS is shown on Fig. 4a while Arrhenius plots for both samples are displayed on Fig. 4b. The high frequency part of the EIS spectrum showing a half circle was attributed to the electrolyte response and the low frequency region was associated to the electrode/electrolyte interface contribution. As responses of both the bulk and the grain boundaries are probably in the same frequency range, the two contributions cannot be separated and solely the total ionic conductivity was reported.

At room temperature we measured total conductivities $\sigma_{\text {Total }}=1.6 \times 10^{-4}{\mathrm{~S} . \mathrm{cm}^{-1}}^{-1}$ and $0.9 \times 10^{-4}$ S.cm ${ }^{-1}$ for S1-SPS and S2-SPS respectively, comparable to the ones reported in literature [17, 21]. Activation energies $\left(E_{a}\right)$ extracted from Arrhenius plots were $E_{a}=0.46 \mathrm{eV}$ and $0.42 \mathrm{eV}$ for S1-SPS and S2-SPS, respectively, slightly higher than reported values [3, 12, 15]. 
However our values are probably reflecting the global activation energy, increased by the contribution of the less conductive $\mathrm{LaAlO}_{3}$ impurity. Similarly, Yamada et al. [17] measured a higher activation energy for grain boundaries $(0.453 \mathrm{eV})$ compared to bulk $(0.364 \mathrm{eV})$.

\subsection{Microscopic Li dynamics}

To get more insight into microscopic Li dynamics of the LLAZO pellets, we performed ${ }^{7} \mathrm{Li}$ wideline NMR experiments between -123 and $227^{\circ} \mathrm{C}$.

For all samples, the linewidth obtained from spectrum deconvolution (see Fig. S2) decreased with temperature as shown on Fig. 5. This so-called motional narrowing occurring during sample heating reflects the faster $\mathrm{Li}^{+}$ions diffusion in the structure as the temperature increases, thus averaging effects of local fields $\left({ }^{7} \mathrm{Li}-{ }^{7} \mathrm{Li}\right.$ dipolar and ${ }^{7} \mathrm{Li}$ quadrupolar interactions). The onset temperature of the motional narrowing process denoted $\mathrm{T}^{\mathrm{MN}}$ (i.e. the temperature corresponding to the inflexion point) is the relevant information and can be linked to the activation energy of the Li hopping process by the empirical expression of Waugh and Fedin [11]:

$$
E_{a}=1.617 \times 10^{-3} \times T^{M N}(K)
$$

Moreover, motional narrowing experiments give also access to an estimate of the mean $\mathrm{Li}$ jump rate $\left(\tau^{-1}\right)$ at $\mathrm{T}^{\mathrm{MN}}$, using the relation:

$$
\tau^{-1} \sim 2 \pi \Delta \delta_{0}
$$

with $\Delta \delta_{0}$ representing the central line width at the inflexion point $[11,12]$.

Importantly, we observed a significant shift of the onset temperature $\mathrm{T}^{\mathrm{MN}}$ toward lower temperatures after SPS treatment for both crushed pellets. The onset temperature was lowered by $130 \mathrm{~K}$ for $\mathrm{S} 1$ and $100 \mathrm{~K}$ for S2 after SPS. Following equation (1) this implies that the activation energy for Li motion decreases by approximatively one third of its value after SPS 
treatment, and using equation (2), that higher temperature is needed to reach a mean Li jump rate of $\sim 10^{4} \mathrm{~s}^{-1}$ in powders compared to SPS sintered samples. It is worth noting that comparable values of $\mathrm{T}^{\mathrm{MN}}$ were observed for S1-SPS and S2-SPS samples, reflecting equivalent Li dynamics in both sintered samples. This is probably related to the similar Li and Al distributions found for both samples after SPS treatment as shown in the next section.

\section{5. $\mathrm{Li}^{+}$and $\mathrm{Al}^{3+}$ site occupancies investigated by MAS NMR}

$\mathrm{Li}^{+}$and $\mathrm{Al}^{3+}$ site occupancies were obtained through ${ }^{6} \mathrm{Li}$ and ${ }^{27} \mathrm{Al}$ MAS NMR spectra analysis on S1 and S1-SPS (Fig. 6) and S2 and S2-SPS (Fig. 7).

Two peaks are expected in ${ }^{6} \mathrm{Li}$ MAS NMR spectra of garnet samples from the literature [9]. A first peak was observed at around $0.1 \mathrm{ppm}$ which is attributed to Li located in the $24 \mathrm{~d}$ tetrahedral sites of the garnet structure while a second peak at $\sim 1.2 \mathrm{ppm}$ is attributed to 48g/96h octahedral sites [9]. Measurements at very-high field (20 T) allowed collection of highly resolved ${ }^{6}$ Li MAS NMR spectra as shown on Fig. 6. Deconvolution of Li band in Fig. S3 provided the site distribution, reported in Table 2. Similar ratio were found for all powders and SPS samples with around $10 \%$ of Li located in $24 \mathrm{~d}$ sites and $90 \%$ in $48 \mathrm{~g} / 96 \mathrm{~h}$ sites. This result shows that SPS did not modify Li distribution among sites. However, a clear narrowing in the peak widths was observed in SPS samples spectra which indicates an increase of Li mobility.

${ }^{27}$ Al MAS NMR spectra are displayed in Fig. 7. In the literature $[1,14,15]$, the two peaks at $\sim 70 \mathrm{ppm}$ and $\sim 82 \mathrm{ppm}$ are attributed to $\mathrm{Al}^{3+}$ located in the $24 \mathrm{~d}$ sites and $48 \mathrm{~g} / 96 \mathrm{~h}$ sites in the garnet phase respectively, 48g and 96h being unresolved as they are neighbor sites (see Fig. 1) [10]. Even though highly distorted $96 \mathrm{~h}$ sites have an approximate 5-fold coordination number, the value of the isotropic chemical shift suggests that $\mathrm{Al}$ ions adopt locally a different coordination geometry than that of Li ions in these sites (4-fold coordination number)[1]. 
In order to fit the ${ }^{27} \mathrm{Al}$ MAS NMR spectra, MQMAS experiments were performed to obtain better information of the NMR parameters. As shown in Fig. S5, the two-dimensional spectra clearly revealed a distribution of the NMR parameters, mostly for the isotropic chemical shift. Such a dispersion can be ascribed to the local disorder in terms of Li sites occupancies. Additional MAS NMR experiments at high temperature showed indeed a narrowing when increasing the temperature (data not shown). Here, it was found that using a distribution of NMR parameters chosen as a product of three Gaussian distributions $\pi(\delta i s o, C Q, \eta)=G(\delta i s o) \times G(C Q) \times G(\eta)$ yielded a very satisfactory fit of the MQMAS spectra as shown in Fig. S6. The NMR parameters were then allowed to vary within 10\% from the obtained values to fit the MAS spectra.

We report in Table S2 the mean and standard deviation value of each NMR parameters, namely the quadrupolar coupling constant $C Q$, the quadrupolar asymmetry parameter $\eta$ and the isotropic chemical shift $\delta$ iso.

The low asymmetry parameter $(\eta=0.2)$ found for all samples for the $70 \mathrm{ppm}$ peak is consistent with the axial symmetry of tetrahedral $24 \mathrm{~d}$ sites. $\eta$ is higher for the $82 \mathrm{ppm}$ peak ( $\eta$ $\sim 0.9$ ) which is more consistent with $48 \mathrm{~g} / 96 \mathrm{~h}$ sites where $\mathrm{Al}^{3+}$ ions can be as well on a centered or on an off-centered position depending on the repulsion interactions with neighboring ions $\left(\mathrm{Li}^{+}\right.$and $\left.\mathrm{Al}^{3+}\right)$ [10]. In ${ }^{27} \mathrm{Al}$ MQMAS NMR experiments conducted at room temperature no other sites were detected (see Fig. S5).

In Fig. 7 we observed a third peak at $12 \mathrm{ppm}$ which is attributed to $\mathrm{Al}$ in the $\mathrm{LaAlO}_{3}$ impurity phase $[10,12]$. It can be noticed that after SPS this peak was strongly lowered for both samples (Table 2). This is consistent with XRD observations and suggests again that SPS promoted conversion of $\mathrm{LaAlO}_{3}$ into $\mathrm{LLAZO}$ and thus $\mathrm{Al}$ insertion in the garnet structure. From our experimental spectra, occupancy of $\mathrm{Al}^{3+}$ sites in the garnet phase was further estimated after removal of the $\mathrm{LaAlO}_{3}$ contribution. It was found for S1 that nearby all $\mathrm{Al}^{3+}$ 
ions were located on $24 \mathrm{~d}$ sites whereas they were distributed in S2 between both sites, 34\% located in $48 \mathrm{~g} / 96 \mathrm{~h}$ sites and $66 \%$ in $24 \mathrm{~d}$ sites (Table 2 ).

NMR clearly shows that Al ion distribution is significantly modified after SPS for both doped samples. For S1-SPS, data show that nearby $20 \%$ of $\mathrm{Al}^{3+}$ ions moved from $24 \mathrm{~d}$ to $48 \mathrm{~g} / 96 \mathrm{~h}$ sites. For S2-SPS, the $\mathrm{Al}^{3+}$ occupancy of $48 \mathrm{~g} / 96 \mathrm{~h}$ sites decreased to $11 \%$ and $\mathrm{Al}^{3+}$ occupancy of $24 \mathrm{~d}$ sites increased to $89 \%$. Al distribution is therefore considerably affected by SPS treatment contrary to what was observed for $\mathrm{Li}^{+}$.

The location of $\mathrm{Al}^{3+}$ ions impacts the Li mobility as Coulombic repulsions induced by $\mathrm{Al}^{3+}$ ions block surrounding sites for Li hops. When Al occupies a 24d site, four octahedral (48g/96h) sites are blocked while when $\mathrm{Al}$ is located on a $48 \mathrm{~g} / 96 \mathrm{~h}$ site only two $24 \mathrm{~d}$ sites are blocked [22]. Interestingly we noticed that after SPS treatment the resulting Al distribution among sites were similar for both powders ( $\sim 85 \%$ in $24 \mathrm{~d}$ and $\sim 15 \%$ in $48 \mathrm{~g} / 96 \mathrm{~h}$ sites).

From the measured $\mathrm{Al}$ and Li relative occupancies and composition data from ICP, knowing the structural data of cubic garnet crystallographic phase, an attempt was made to calculate the remaining proportion of vacancies on each site. It should however only being considered as an estimate and DFT calculations would help at clarifying the $48 \mathrm{~g} / 96 \mathrm{~h}$ effective site splitting. We considered here that two $\mathrm{Al}^{3+}$ or one $\mathrm{Al}^{3+}$ and one $\mathrm{Li}^{+}$cannot simultaneously occupy neighboring $48 \mathrm{~g}$ and $96 \mathrm{~h}$ sites because of high Coulombic repulsion due to short distance between $48 \mathrm{~g}$ and $96 \mathrm{~h}$ sites. Therefore, our calculations considered $96 \mathrm{~h} / 48 \mathrm{~g} / 96 \mathrm{~h}$ as a single site. The results are presented in Fig. 8, and confirm the strong similarity between the two powders following SPS treatment.

Very little vacancies were found for $48 \mathrm{~g} / 96 \mathrm{~h}$ octahedral sites in both samples $(<3 \%)$, whereas a majority of vacancies were located on the $24 d$ tetrahedral sites $(\sim 70 \%)$. These site occupancies are consistent with Figure 5 of [23]. 
To sum up, we showed that the SPS treatment leads to (i) a strong reduction of $\mathrm{LaAlO}_{3}$ impurity, (ii) Al inclusion in the garnet phase, (iii) a redistribution of Al ions among available sites and (iv) a significant lowering of the motional narrowing onset temperature. We therefore infer that SPS, besides being a fast and extremely performant densification process, induces profound modifications in the sintered material. The combination of all the effects mentioned above are responsible for the increased ion mobility in the SPS-sintered Al-doped garnets.

Moreover, even though the Al content increased in the samples after SPS treatment (section 3.2), it should not be considered as the main reason for the great enhancement in Li mobility since S1 has a similar Al content compared to S2-SPS but not such high Li mobility.

$\mathrm{Al}$ insertion in the garnet phase and ion redistribution into available sites may be related to an electromigration process during SPS treatment, mainly on $\mathrm{Al}^{3+}$ as it is more sensitive to electric fields compared to $\mathrm{Li}^{+}$. Although not reported yet, this process should be correlated to electromigration mitigated effects such as carbon insertion [17], Frenkel pair nucleation [26] or oxygen gradient in $\mathrm{UO}_{2+\mathrm{x}}$ [27]. Moreover the extremely fast cooling rate used in SPS sintering could have quenched the system into a metastable state with highly disordered ionic distribution, favoring high Li mobility [5, 25, 28-29].

However this assumption would need further investigations through calculations such as ab initio and molecular dynamics to get a deeper understanding on the effect of SPS on ionic distribution. Comparison with hot pressing sintering method could also help at clarifying the SPS effect, even though grain growth will occur due to the longer duration of the sintering process. 


\section{Conclusions}

In this study, we have prepared cubic LLAZO with two Al doping levels. XRD measurements confirmed the synthesis of the more conducting cubic phase, and following SPS treatment, ionic conductivity measured by EIS on densified pellets was found in the range of $\sim 10^{-4} \mathrm{~S}_{\mathrm{cm}} \mathrm{cm}^{-}$ ${ }^{1}$ at $25{ }^{\circ} \mathrm{C} .{ }^{27} \mathrm{Al}$ MAS NMR revealed that a redistribution of $\mathrm{Al}$ ions between available sites occurred after SPS without affecting the cubic phase as confirmed by XRD. Moreover, by means of temperature-variable ${ }^{7} \mathrm{Li}$ static NMR, it was observed that SPS treatment significantly decreases the motional narrowing onset temperature $\mathrm{T}^{\mathrm{MN}}$ by $\sim 100 \mathrm{~K}$ in comparison with the pristine powders, demonstrating that bulk mobility of Li was strongly enhanced by SPS.

This study reveals that the enhancement of the total ionic conductivity of SPS sintered samples is not only due to a better densification that effectively restrains porosity effect but also results from an increased bulk ionic conductivity caused by modified Al site occupancies that favor higher Li mobility.

These observations should be extended to a wider range of doping levels and various conducting ceramics, and demonstrate also how NMR studies help at understanding the underlying mechanisms of SPS treatment.

\section{Acknowledgments}

Authors thanks Junxian Zhang (ICMPE, Thiais, France) for ICP measurements and Enrique Vega (NIMBE, Saclay, France) for SEM. Financial support from the TGIR-RMN-THC Fr3050 CNRS for conducting the ${ }^{6} \mathrm{Li}$ MAS NMR measurements is gratefully acknowledged. Authors are also very grateful to Pierre-Marie Geffroy (IRCER, Limoges, France) for fruitful discussions and Magali Gauthier (NIMBE, Saclay, France) for careful rereading of the text. 


\section{Appendix A. Supplementary material}

Attached file

\section{References}

[1] C. A. Geiger, E. Alekseev, B. Lazic, M. Fisch, T. Armbruster, R. Langner, M. Fechtelkord, N. Kim, T. Pettke, W. Weppner, Crystal chemistry and stability of $\mathrm{Li}_{7} \mathrm{La}_{3} \mathrm{Zr}_{2} \mathrm{O}_{12}$ garnet: A fast lithium-ion conductor, Inorg. Chem. 50 (2011) 1089-1097.

[2] R. Murugan, V. Thangadurai, W. Weppner, Fast lithium ion conduction in garnet-type $\mathrm{Li}_{7} \mathrm{La}_{3} \mathrm{Zr}_{2} \mathrm{O}_{12}$, Angew. Chem. Int. Ed. 46 (2007) 7778-7781.

[3] Y. Matsuda, K. Sakamoto, M. Matsui, O. Yamamoto,Y. Takeda, N. Imanishi, Phase formation of a garnet-type lithium-ion conductor $\mathrm{Li}_{7-3 x} \mathrm{Al}_{\mathrm{x}} \mathrm{La}_{3} \mathrm{Zr}_{2} \mathrm{O}_{12}$, Solid State Ionics 277 (2015) 23-29.

[4] N. Bernstein, M. D. Johannes, K. Hoang, Origin of the structural phase transition in $\mathrm{Li}_{7} \mathrm{La}_{3} \mathrm{Zr}_{2} \mathrm{O}_{12}$, Phys. Rev. Lett. 109 (2012) 2-6.

[5] Y. Matsuda, Y. Itami, K. Hayamizu, T. Ishigaki, M. Matsui,Y. Takeda, O.Yamamoto, N. Imanishi, Phase relation, structure and ionic conductivity of $\mathrm{Li}_{7-\mathrm{x}-3 \mathrm{y}} \mathrm{Al}_{\mathrm{y}} \mathrm{La}_{3} \mathrm{Zr}_{2-\mathrm{x}} \mathrm{Ta}_{\mathrm{x}} \mathrm{O}_{12}, \mathrm{RSC}$ Adv. 6 (2016) 78210-78218.

[6] Y.Li, J.- T. Hanc, C.- A. Wanga, S. C. Vogelc, H. Xieb, M. Xub, J. B. Goodenough, Ionic distribution and conductivity in lithium garnet $\mathrm{Li}_{7} \mathrm{La}_{3} \mathrm{Zr}_{2} \mathrm{O}_{12}$, J. Power Sources 209 (2012) 278-281.

[7] R. Jalem, Y. Yamamoto, H. Shiiba, M. Nakayama, H. Munakata, T.Kasuga, K. Kanamura, Concerted migration mechanism in the $\mathrm{Li}$ ion dynamics of garnet-type $\mathrm{Li}_{7} \mathrm{La}$ ${ }_{3} \mathrm{Zr}_{2} \mathrm{O}_{12}$, Chem. Mater. (2013) 425-430.

[8] M. Xu, M. S. Park, J. M. Lee, T. Y. Kim, Y. S. Park, E. Ma, Mechanisms of Li + transport in garnet-type cubic $\mathrm{Li}_{3{ }^{+}} \mathrm{La}_{3} \mathrm{M}_{2} \mathrm{O}_{12}(\mathrm{M}=\mathrm{Te}, \mathrm{Nb}, \mathrm{Zr})$, Phys. Rev. B - Condens. Matter Mater. Phys. 85 (2012) 1-5.

[9] L. van Wüllen, T. Echelmeyer, H.-W. Meyer, D. Wilmer, The mechanism of Li-ion transport in the garnet $\mathrm{Li}_{5} \mathrm{La}_{3} \mathrm{Nb}_{2} \mathrm{O}_{12}$, Phys. Chem. Chem. Phys. 9 (2007) 3298-3303.

[10] D. Rettenwander, P. Blaha, R.Laskowski, K. Schwarz, P. Bottke, M. Wilkening, C. A. Geiger, G. Amthauer, DFT Study of the Role of Al 3+ in the Fast Ion-Conductor $\mathrm{Li}_{7-3} \mathrm{x}_{\mathrm{Al}} \mathrm{I}_{3+}$ ${ }_{x} \mathrm{La}_{3} \mathrm{Zr}_{2} \mathrm{O}_{12}$ Garnet, Chem. Mater. 26 (2014) 2617-2623.

[11] A. Kuhn, S. Narayanan, L. Spencer, G. Goward, V. Thangadurai, M. Wilkening, Li self-diffusion in garnet-type $\mathrm{Li}_{7} \mathrm{La}_{3} \mathrm{Zr}_{2} \mathrm{O}_{12}$ as probed directly by diffusion-induced Li7 spinlattice relaxation NMR spectroscopy, Phys. Rev. B - Condens. Matter Mater. Phys. 83 (2011) $1-11$.

[12] H. Buschmann, J. Dölle, S. Berendts, A. Kuhn, P. Bottke, M. Wilkening, P. Heitjans, A. Senyshyn, H.Ehrenberg, A. Lotnyk, V. Duppel, L. Kienle, J. Janek, Structure and dynamics of the fast lithium ion conductor $\mathrm{Li}_{7} \mathrm{La}_{3} \mathrm{Zr}_{2} \mathrm{O}_{12}$, Phys. Chem. Chem. Phys. 13 (2011) 19378. 
[13] A. Kuhn, J.- Y. Choi, L. Robben, F. Tietz, M. Wilkening, P. Heitjans, Li Ion Dynamics in Al-Doped Garnet-Type $\mathrm{Li}_{7} \mathrm{La}_{3} \mathrm{Zr}_{2} \mathrm{O}_{12}$ Crystallizing with Cubic Symmetry, Zeitschrift für Phys. Chemie 226 (2012) 525-537.

[14] A. A. Hubaud, D. J. Schroeder, B. Key, B. J. Ingram, F. Dogan, J. T. Vaughey, Low temperature stabilization of cubic $\left(\mathrm{Li}_{7-\mathrm{x}} \mathrm{Al}_{\mathrm{x} / 3}\right) \mathrm{La}_{3} \mathrm{Zr}_{2} \mathrm{O}_{12}$ : role of aluminum during formation, J. Mater. Chem. A 1 (2013) 8813.

[15] Y. Zhang, F. Chen, R. Tu, Q. Shen, X. Zhang, L. Zhang, Effect of lithium ion concentration on the microstructure evolution and its association with the ionic conductivity of cubic garnet-type nominal $\mathrm{Li}_{7} \mathrm{All}_{.25} \mathrm{La}_{3} \mathrm{Zr}_{2} \mathrm{O}_{12}$ solid electrolytes, Solid State Ionics 284 (2016) 53-60.

[16] A. Düvel, A. Kuhn, L. Robben, M. Wilkening, P. Heitjans, Mechanosynthesis of Solid Electrolytes: Preparation, Characterization, and Li Ion Transport Properties of Garnettype Al-doped $\mathrm{Li}_{7} \mathrm{La}_{3} \mathrm{Zr}_{2} \mathrm{O}_{12}$ Crystallizing with Cubic Symmetry, J. Phys. Chem. C 116 (2012) 15192-15202.

[17] H. Yamada, T. Ito, R. Hongahally Basappa, Sintering Mechanisms of HighPerformance Garnet-type Solid Electrolyte Densified by Spark Plasma Sintering, Electrochim. Acta 222 (2016) 648-656.

[18] R. Kali and A. Mukhopadhyay, Spark plasma sintered/synthesized dense and nanostructured materials for solid-state Li-ion batteries: Overview and perspective, J. Power Sources 247 (2014) 920-931.

[19] H. Yamada, T. Ito, R. Hongahally Basappa, Sintering Mechanisms of HighPerformance Garnet-type Solid Electrolyte Densified by Spark Plasma Sintering, Electrochim. Acta 222 (2016) 648-656.

[20] H. Geng et al., Formation Mechanism of Garnet-Like $\mathrm{Li}_{7} \mathrm{La}_{3} \mathrm{Zr}_{2} \mathrm{O}_{12}$ Powder Prepared by Solid State Reaction, Rare Met. Mater. Eng. 45 (2016) 612-616.

[21] M. Botros, R. Djenadic, O. Clemens, M. Möller, H. Hahn, Field assisted sintering of fine-grained $\mathrm{Li}_{7-3 \mathrm{x}} \mathrm{La}_{3} \mathrm{Zr}_{2} \mathrm{Al}_{\mathrm{x}} \mathrm{O}_{12}$ solid electrolyte and the influence of the microstructure on the electrochemical performance, J. Power Sources 309 (2016) 108-115.

[22] D. O. Shin et al., Synergistic multi-doping effects on the $\mathrm{Li}_{7} \mathrm{La}_{3} \mathrm{Zr}_{2} \mathrm{O}_{12}$ solid electrolyte for fast lithium ion conduction, Sci. Rep. 5 (2016) 18053.

[23] V. Thangadurai, S. Narayanan, D. Pinzaru, Garnet-type solid-state fast Li ion conductors for Li batteries: critical review, Chem. Soc. Rev. 43 (2014) 4714.

[24] C. Chen, Z. Lu, F. Ciucci, Data mining of molecular dynamics data reveals Li diffusion characteristics in garnet $\mathrm{Li}_{7} \mathrm{La}_{3} \mathrm{Zr}_{2} \mathrm{O}_{12}$, Sci. Rep. 7 (2017) 40769.

[25] K. Meier, T. Laino, A. Curioni, Solid-state electrolytes: Revealing the mechanisms of Li-Ion conduction in tetragonal and cubic LLZO by first-principles calculations, J. Phys.

Chem. C 118 (2014) 6668-6679.

[26] M. Cologna, J.S.C. Francis, R. Raj, Field assisted and flash sintering of alumina and its relationship to conductivity and MgO-doping, J. Eur. Ceram. Soc. 31(2011) 2827-2837. 
[27] V. Tyrpek1, M. Naji, M. Holzhäuser, D. Freis, D. Prieur, P. Martin, B. Cremer, M. Murray-Farthing, M. Cologna, On the Role of the Electrical Field in Spark Plasma Sintering of $\mathrm{UO}_{2+x}$, Sci. Rep. 7 (2017) 46625.

[28] M. Burbano, D. Carlier, F. Boucher, B. J. Morgan, M. Salanne, Sparse Cyclic Excitations Explain the Low Ionic Conductivity of Stoichiometric $\mathrm{Li}_{7} \mathrm{La}_{3} \mathrm{Zr}_{2} \mathrm{O}_{12}$, Phys. Rev. Lett. 116 (2016) 1-6.

[29] V. Petříček, M. Dušek, L. Palatinus, Crystallographic Computing System JANA2006: General features. Z. Kristallogr. - Cryst. Mater. 229 (2014) 345- 352. 


\section{Figure captions}

Fig. 1. (a) Crystal structure of cubic-type LLAZO (Ia-3d) (ICSD \#238690). (b) Li tetrahedral (24d) and octahedral (48g/96h) site connections.

Fig.2: X-ray diffraction patterns of S1, S2, S1-SPS and S2-SPS samples collected with Cu$\mathrm{K}_{\alpha 1,2}$ radiations.

Fig. 3: Backscattered SEM images of (a) S1 powder, (b) S2 powder, (c) polished S1-SPS, (d) polished S2-SPS.

Fig. 4. (a) Nyquist plots of S1-SPS impedance at $44^{\circ} \mathrm{C}$ and equivalent circuit; (b) Arrhenius plot of total ionic conductivity of LLAZO samples.

Fig.5. ${ }^{7} \mathrm{Li}$ NMR full width at half maximum (FWHM) of the central transition versus temperature for both studied compositions.

Fig. 6. Experimental ${ }^{6} \mathrm{Li}$ MAS NMR spectra of the studied samples recorded at $20 \mathrm{~T}$ and sample spinning frequency of $10 \mathrm{kHz}$.

Fig. 7. Experimental ${ }^{27} \mathrm{Al}$ MAS NMR spectra of the studied samples recorded at magnetic field of $11.72 \mathrm{~T}$ and sample spinning frequency of $12.5 \mathrm{kHz}$.

Fig. 8. Relative occupancy of (a) tetrahedral and (b) octahedral sites by Li, Al and vacancies in LLAZO from deconvoluted spectra of ${ }^{27} \mathrm{Al}$ and ${ }^{6} \mathrm{Li}$ MAS NMR 
Tables

\begin{tabular}{|c|c|c|c|c|c|}
\hline & & S1 & S1-SPS & S2 & S2-SPS \\
\hline $\begin{array}{l}\mathrm{LaAlO}_{3} \text { phas } \\
\text { sample (at.\% }\end{array}$ & the & $5.1(3)$ & $2.9(2)$ & $10.6(6)$ & 1.1(1) \\
\hline & $\mathbf{L i}$ & $56(1)$ & $56(1)$ & $57(1)$ & $54(1)$ \\
\hline Elemental & Al & $2.2(1)$ & $2.4(1)$ & $1.5(1)$ & $2.3(1)$ \\
\hline garnet phase & La & $25(1)$ & $25(1)$ & $25(1)$ & $26(1)$ \\
\hline & $\mathbf{Z r}$ & $17.2(2)$ & $16.8(3)$ & $16.7(3)$ & $17.4(3)$ \\
\hline
\end{tabular}

Table 1. Atomic concentrations (normalized to 100\%) of $\mathrm{Li}, \mathrm{Al}, \mathrm{La}$ and $\mathrm{Zr}$ in the garnet samples and molar content of $\mathrm{LaAlO}_{3}$ (see text).

\begin{tabular}{|c|c|c|c|c|c|}
\hline \multicolumn{6}{|c|}{ Li (at.\%) } \\
\hline & & S1 & S1-SPS & S2 & S2-SPS \\
\hline \multicolumn{2}{|c|}{$\mathrm{Li}$ in $24 \mathrm{~d}$ sites $(0.1 \mathrm{ppm})$} & 10 & 9 & 10 & 9 \\
\hline \multicolumn{2}{|c|}{$\mathrm{Li}$ in $48 \mathrm{~g} / 96 \mathrm{~h}$ sites (1.2 ppm) } & 90 & 91 & 90 & 91 \\
\hline \multicolumn{6}{|c|}{ Al (at.\%) } \\
\hline & & S1 & S1-SPS & S2 & S2-SPS \\
\hline \multicolumn{2}{|c|}{$\mathrm{Al}_{\mathrm{LaAlO}_{3}}(12 \mathrm{ppm})$} & 17 & 9 & 40 & 4 \\
\hline \multirow{2}{*}{$\begin{array}{l}\text { In garnet } \\
\text { phase }\end{array}$} & $\begin{array}{c}\mathrm{Al}_{\text {LLAZO(24d) }}(70 \\
\text { ppm) }\end{array}$ & 99 & 84 & 66 & 90 \\
\hline & $\begin{array}{c}\mathrm{Al}_{\text {LLAZO }(48 \mathrm{~g} / 96 \mathrm{~h})}(82 \\
\mathrm{ppm})\end{array}$ & 1 & 16 & 34 & 10 \\
\hline
\end{tabular}

Table 2. $\mathrm{Li}$ and $\mathrm{Al}$ locations from ${ }^{6} \mathrm{Li}$ and ${ }^{27} \mathrm{Al}$ MAS NMR spectra. Population error is estimated as $1 \%$. 
Figure 1.

(a)

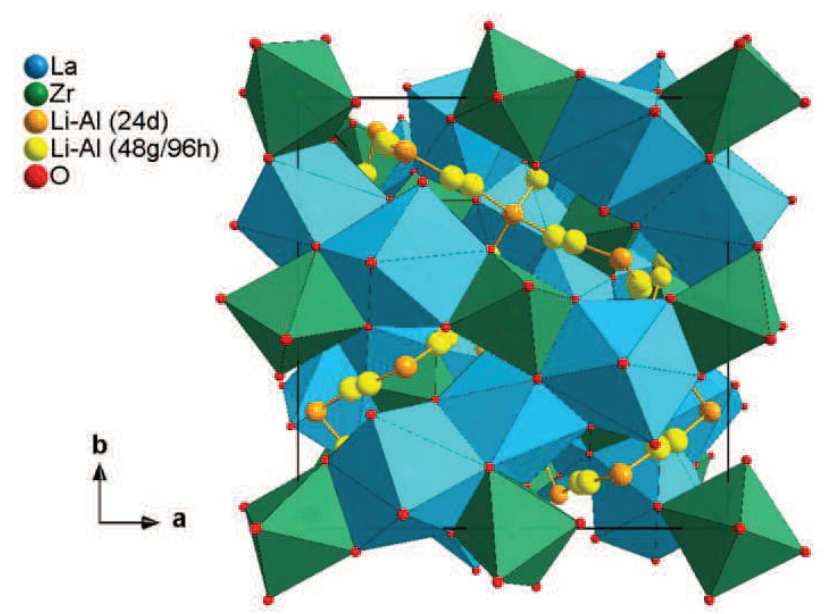

(b)

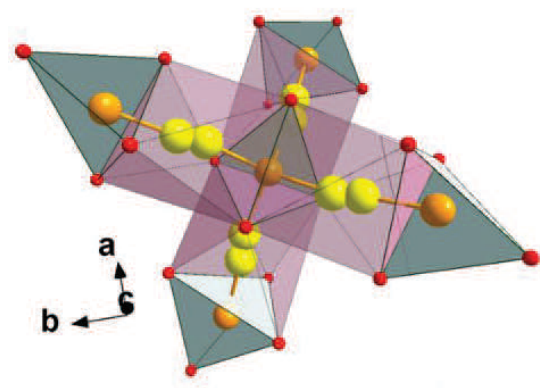


Figure 2.

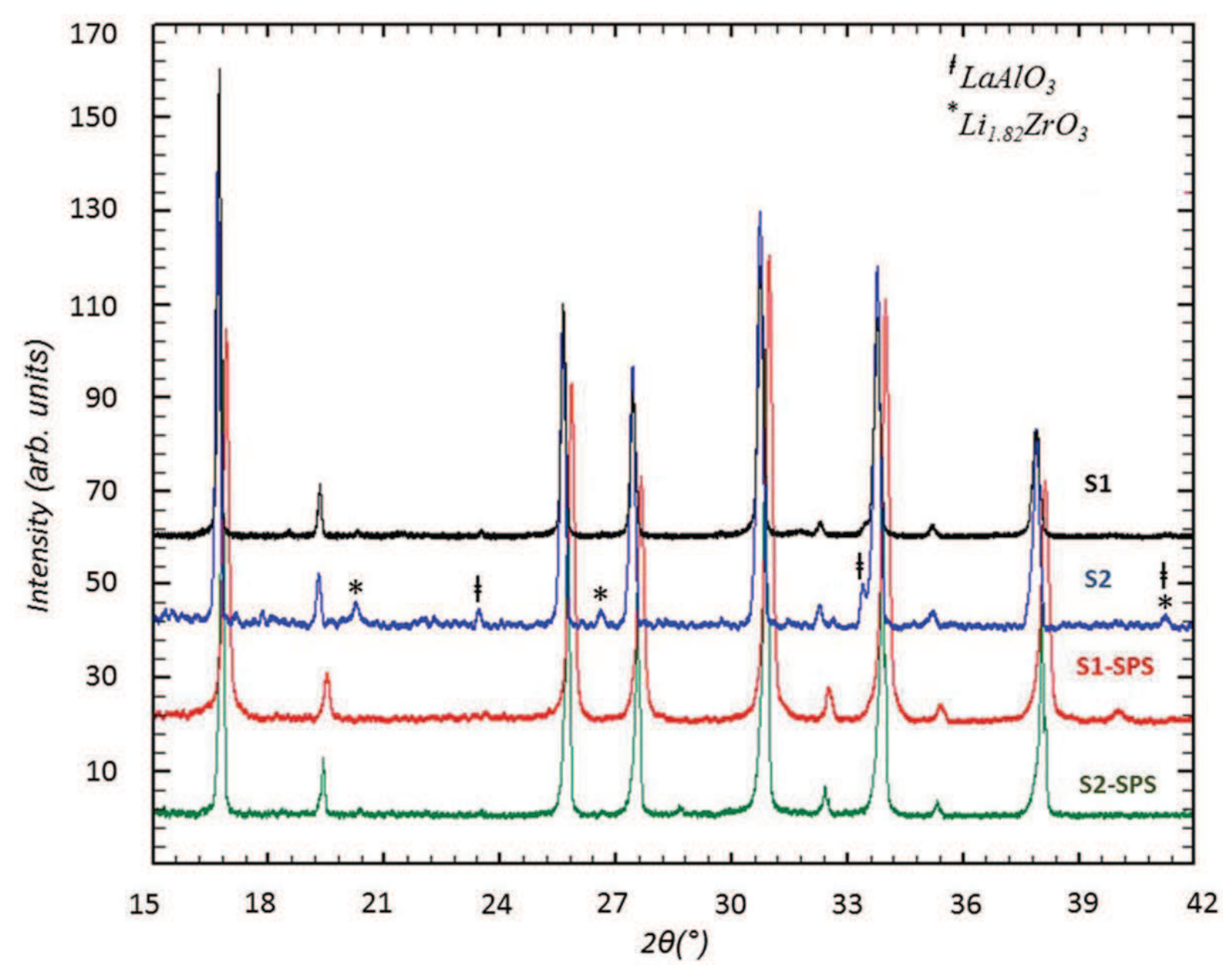


Figure 3.
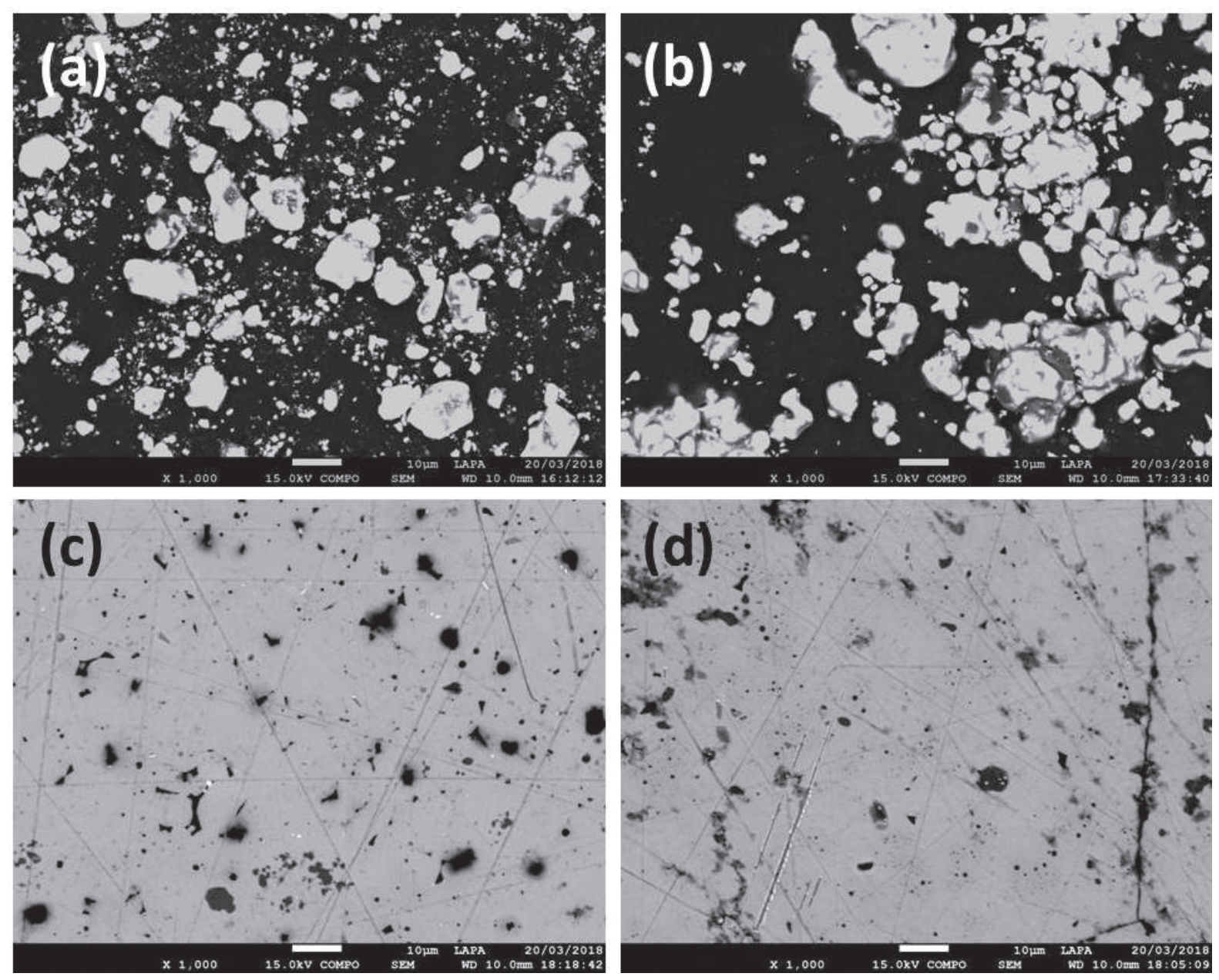
Figure 4.
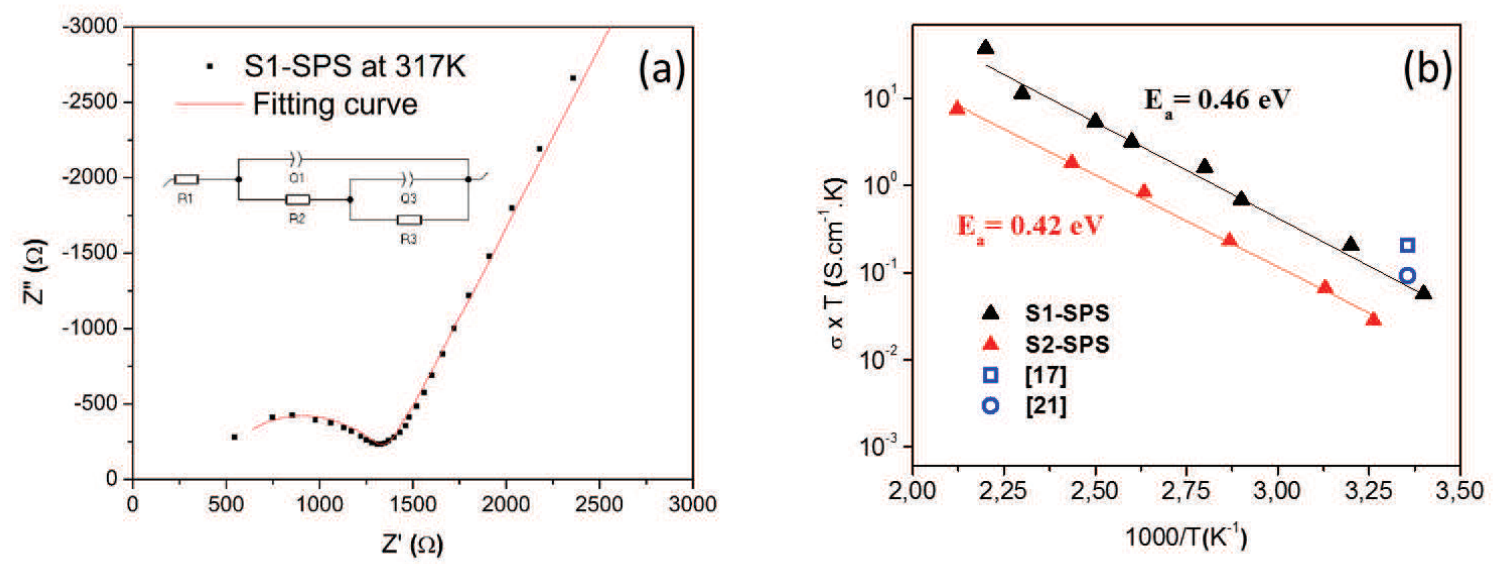
Figure 5.
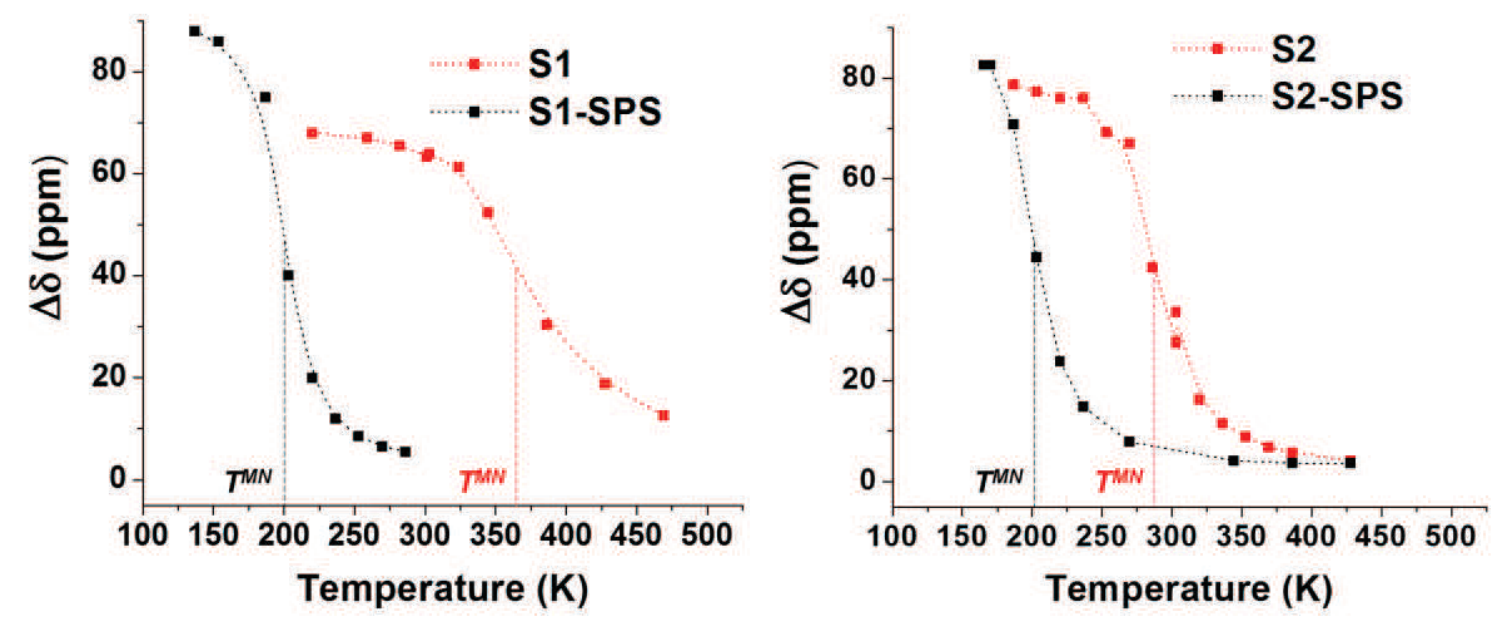
Figure 6.
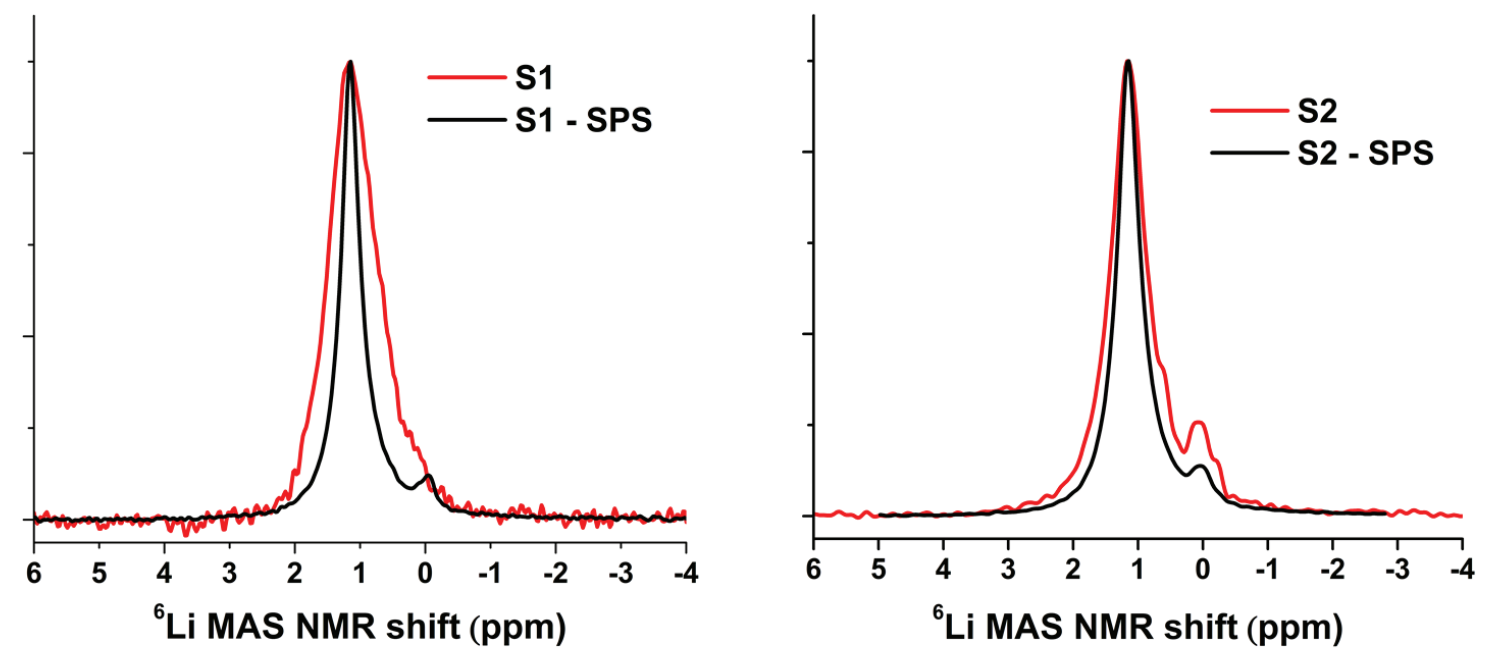
Figure 7.
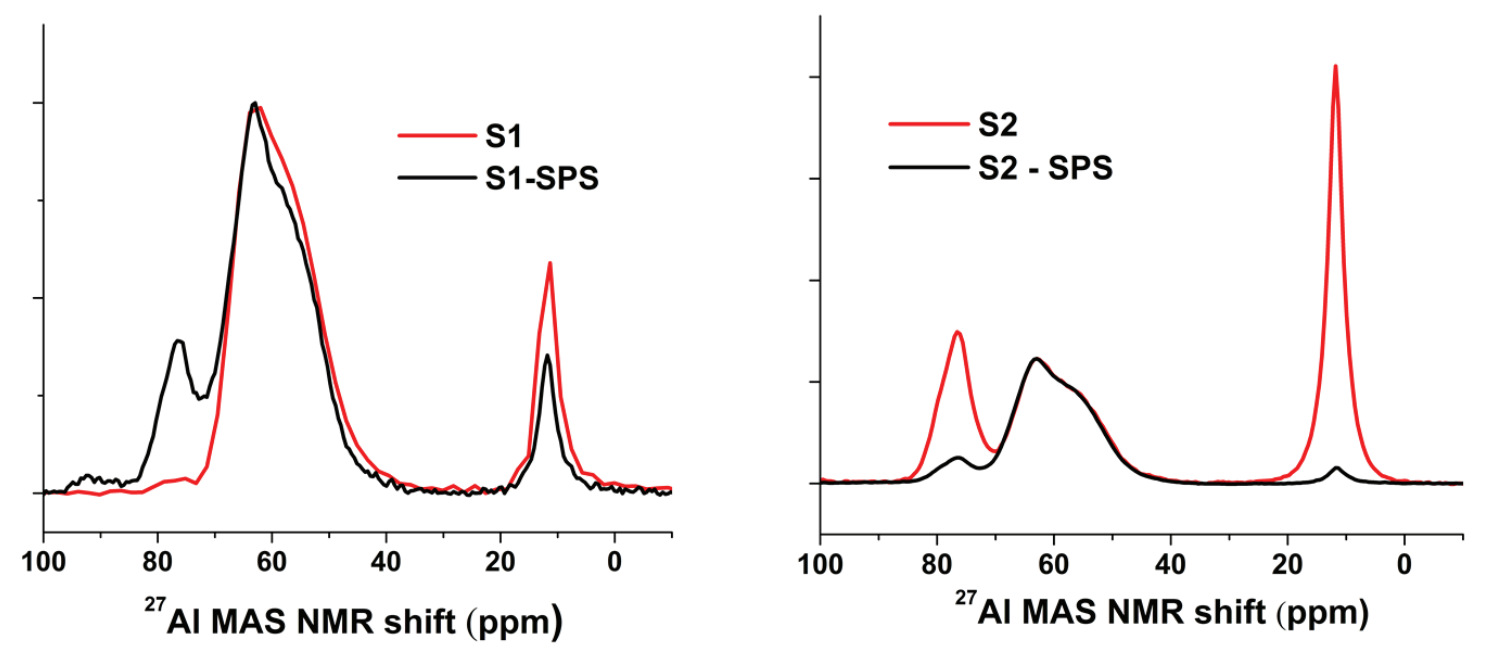

Figure

${ }^{27}$ Al MAS NMR shift (ppm) ${ }^{27}$ AI MAS NMR shift (ppm) 
Figure 8.
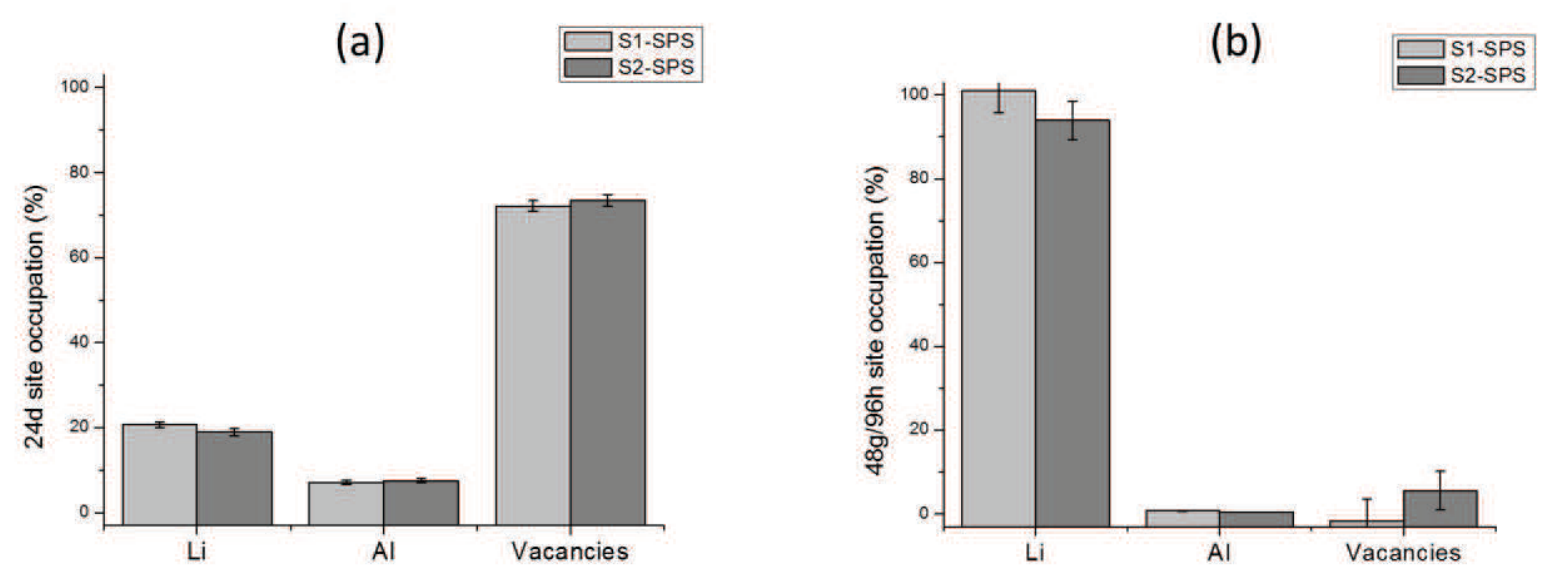


\section{[Supplementary Material]}

Bulk Li mobility enhancement following Spark Plasma Sintering on $\mathrm{Li}_{(7-3 x)} \mathrm{Al}_{\mathrm{x}} \mathrm{La}_{3} \mathrm{Zr}_{2} \mathrm{O}_{12}$ garnet revealed by Nuclear Magnetic Resonance

Adriana Castillo, Thibault Charpentier, Olivier Rapaud, Nicolas Pradeilles, Saïd Yagoubi, Eddy Foy, Mélanie Moskura, Hicham Khodja

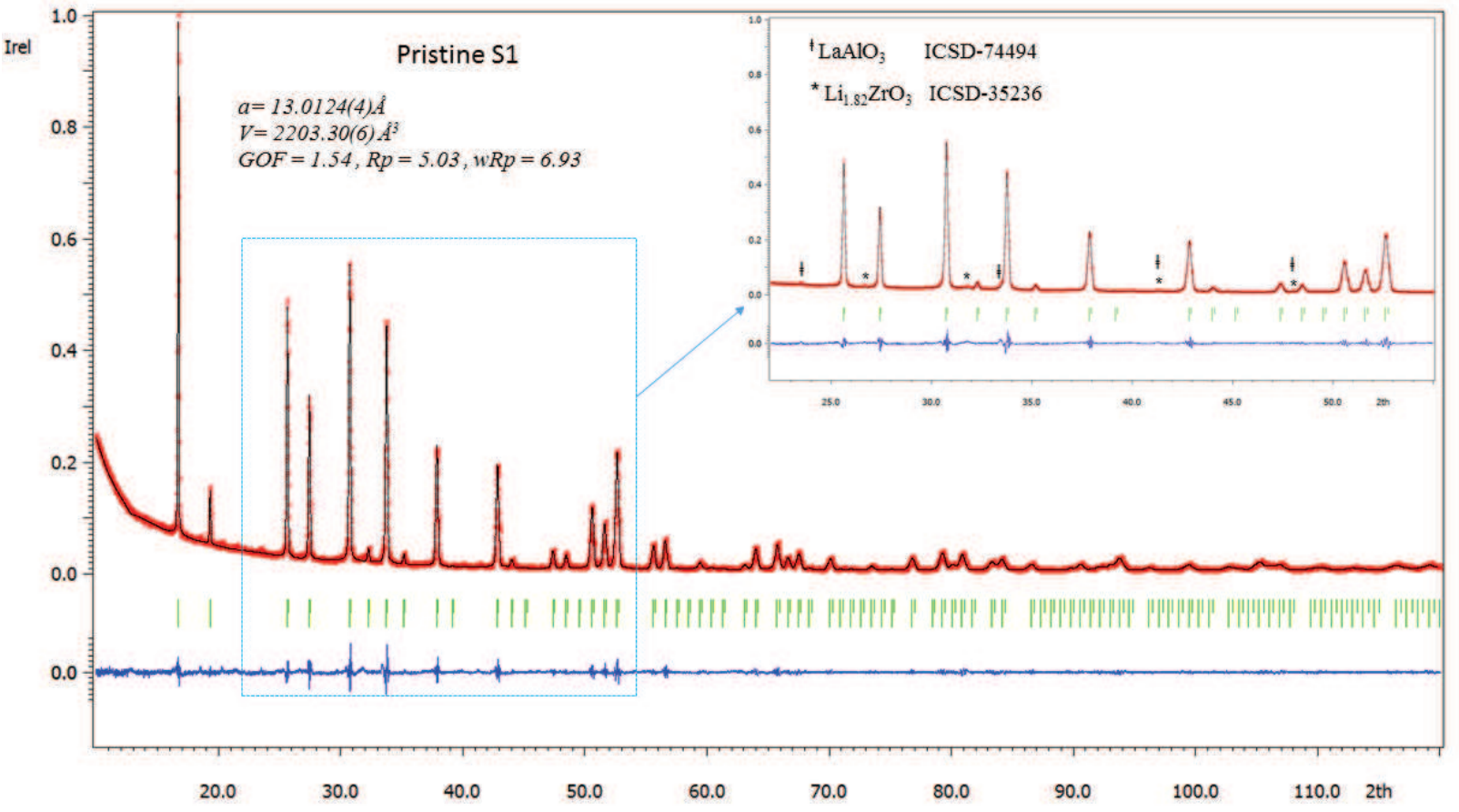

Fig. S1: Calculated scattering intensity profile (black) compared to experimental data (red) for garnet sample S1. For practical reasons, only Lebail refinement for pristine S1 is given. 


\begin{tabular}{|c|c|c|c|c|}
\hline Sample & $S 1$ & S1-SPS & $S 2$ & S2-SPS \\
\hline \multicolumn{5}{|l|}{ Crystal data } \\
\hline Crystal symmetry & \multicolumn{4}{|c|}{ Cubic } \\
\hline Space group & \multicolumn{4}{|c|}{ I a-3d no (230) } \\
\hline Unit cell & $\mathrm{a}=13.0124(4) \AA$ & $a=12.9758(5) \AA$ & $a=12.9870(6) \AA$ & $a=12.9634(3) \AA$ \\
\hline Cell volume & $V=2203.30(6) \AA^{3}$ & $V=2184.75(8) \AA^{3}$ & $V=2190.41(9) \AA^{3}$ & $\mathrm{~V}=2178.52(5) \AA^{3}$ \\
\hline $\mathrm{Z}$ & 8 & 8 & 8 & 8 \\
\hline $\mathrm{Rp}$ & 5.03 & 4.73 & 2.57 & 5.00 \\
\hline wRp & 6.93 & 6.65 & 3.62 & 7.37 \\
\hline GOF & 1.54 & 1.33 & 1.18 & 1.8 \\
\hline
\end{tabular}

Table S1: Crystal data and structure refinement parameters for LLAZO 


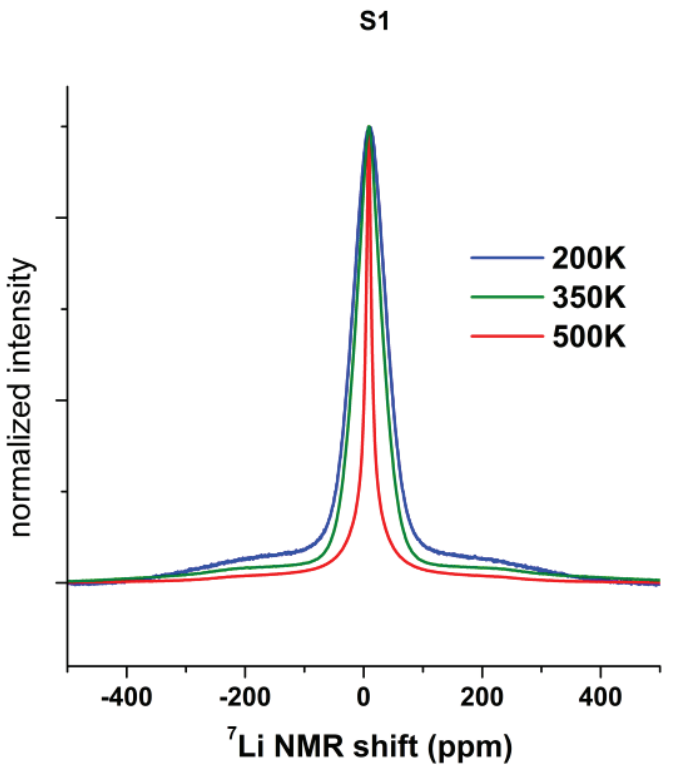

Fig. S2: Experimental ${ }^{7} \mathrm{Li}$ NMR spectra of S1 sample at different temperatures. The spectra are deconvoluted by combining a narrow central line (central transition) and a wider contribution (satellite transitions) with lower intensity.

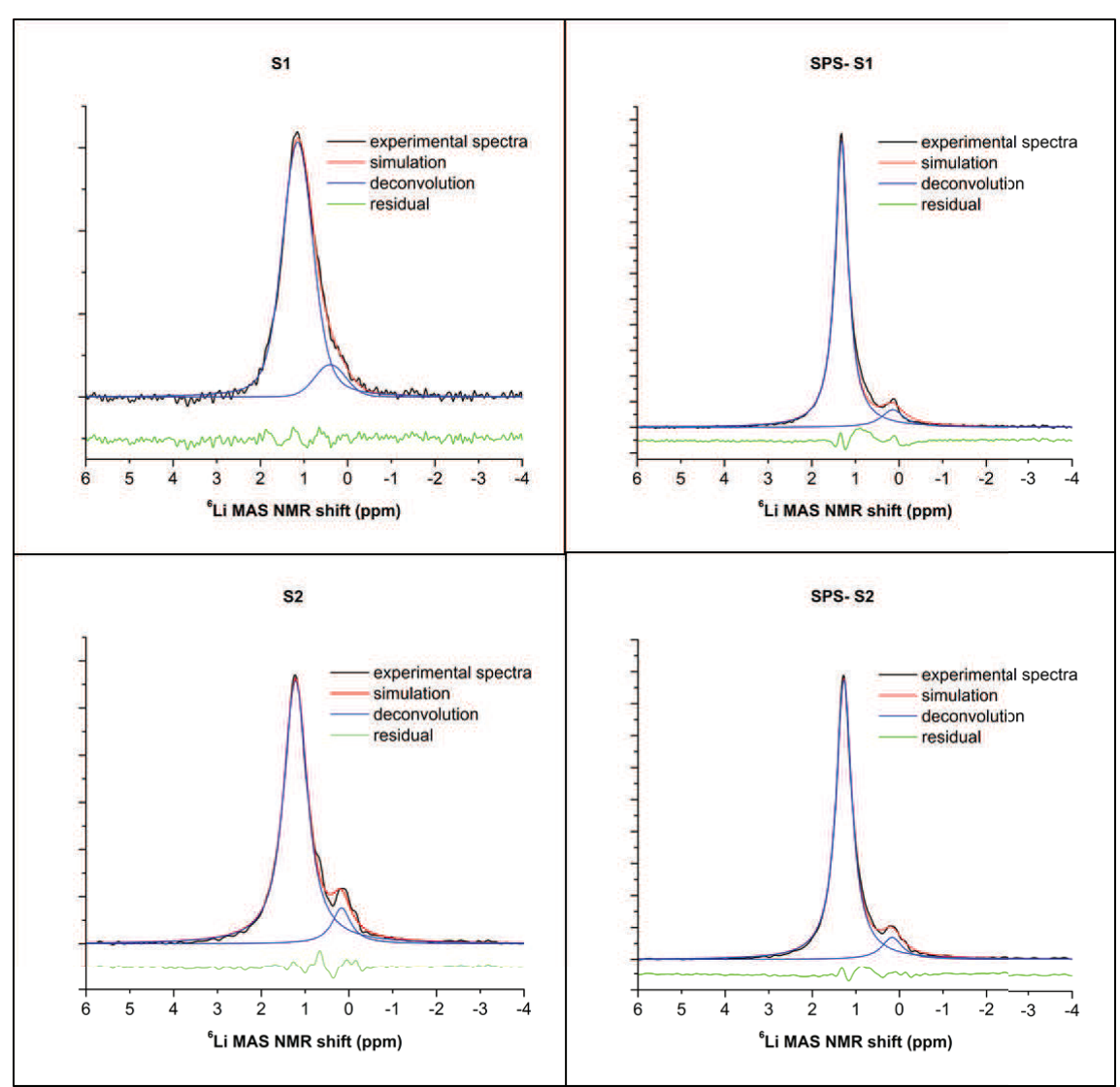

Fig. S3: Experimental and simulated ${ }^{6}$ Li MAS NMR spectra of the studied samples at room temperature. 


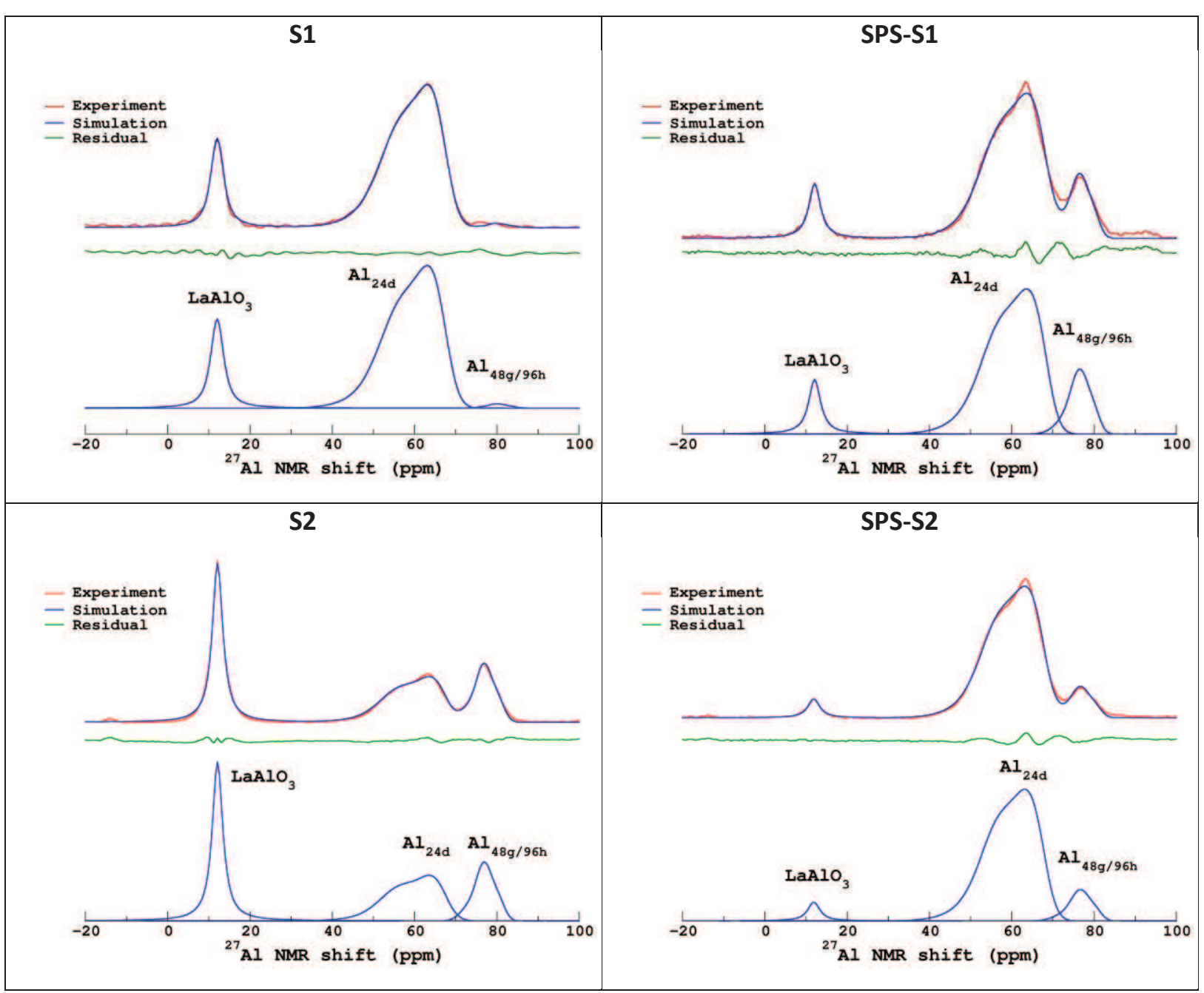

Fig. S4: Experimental and simulated ${ }^{27}$ Al MAS NMR spectra of studied samples at room temperature. 


\begin{tabular}{|c|c|c|c|}
\hline \multirow{2}{*}{ S1 } & \multicolumn{3}{|c|}{$\mathbf{A l}_{\text {LLAZO(24d) }}$} \\
\cline { 2 - 4 } & $\boldsymbol{\delta}_{\text {iso }}(\mathbf{p p m})$ & $\boldsymbol{C}_{\boldsymbol{Q}}(\mathbf{M H z})$ & $\boldsymbol{\eta}$ \\
\hline S1-SPS & $70.0(2.5)$ & $5.5(0.6)$ & $0.2(0.02)$ \\
\hline S2 & $70.9(2.2)$ & $5.5(0.5)$ & $0.3(0.01)$ \\
\hline S2-SPS & $70.3(2.5)$ & $5.5(0.5)$ & $0.2(0.02)$ \\
\hline
\end{tabular}

\begin{tabular}{|c|c|c|c|}
\hline \multirow{2}{*}{ S1 } & \multicolumn{3}{|c|}{ Al $_{\text {LLAZO(48/966h) }}$} \\
\cline { 2 - 4 } & $\boldsymbol{\delta}_{\text {iso }}(\mathbf{p p m})$ & $\boldsymbol{C}_{\boldsymbol{Q}} \mathbf{( M H z )}$ & $\boldsymbol{\eta}$ \\
\hline S1-SPS & n.a $(<1 \%)$ & n.a $(<1 \%)$ & n.a $(<1 \%)$ \\
\hline S2 & $81.4(1.2)$ & $3.3(0.3)$ & $0.9(0.01)$ \\
\hline S2-SPS & $81.8(1.2)$ & $3.3(0.3)$ & $0.8(0.02)$ \\
\hline
\end{tabular}

Table S2: Mean and standard deviation (in parenthesis) values of the ${ }^{27}$ Al MAS NMR parameters distribution obtained from fitted spectra shown in Fig. S4: isotropic chemical shift $\delta_{i s o}$, quadrupolar coupling constant $C_{Q}$ and asymmetry parameter $\eta$. 


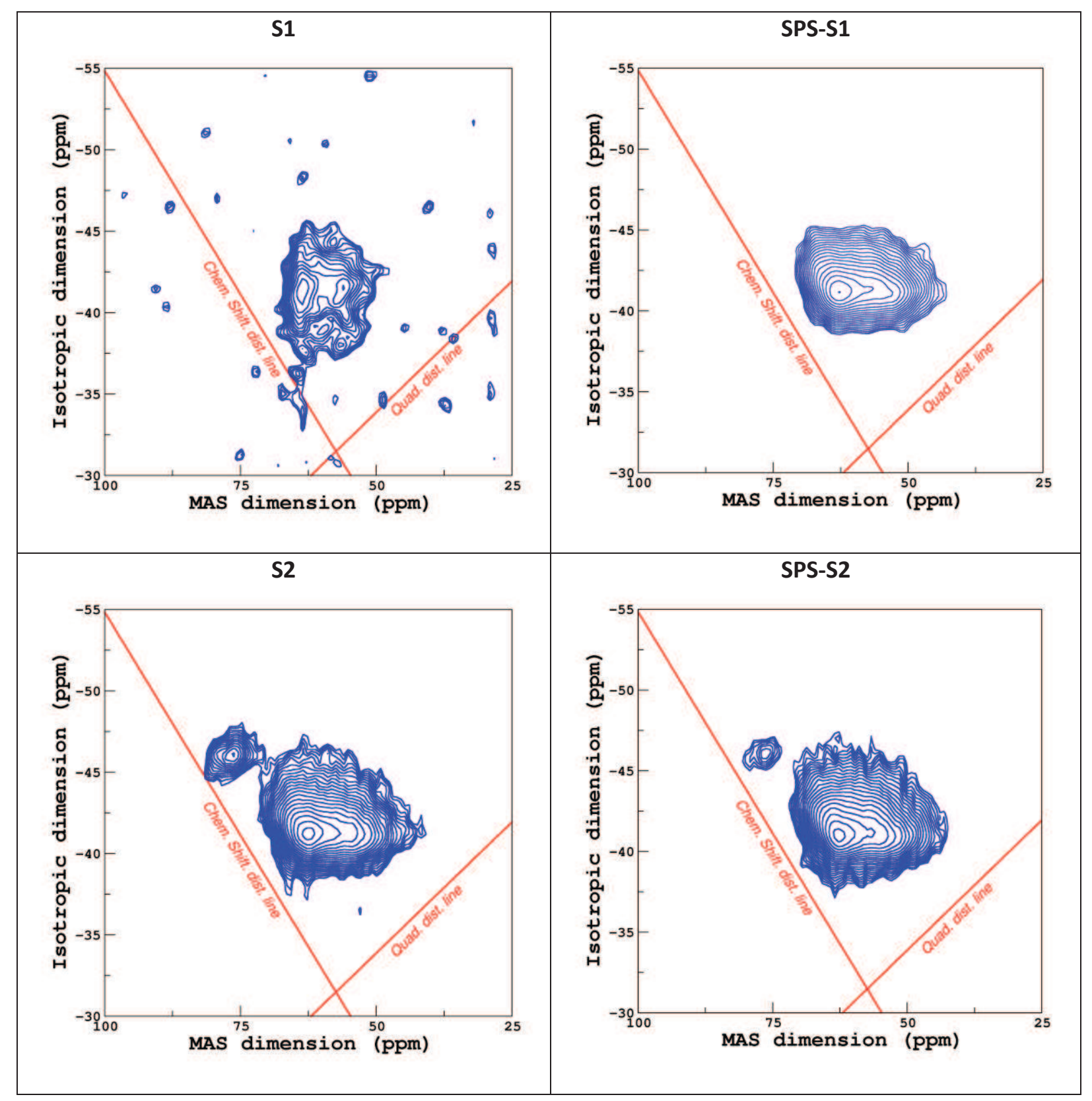

Fig. S5: Experimental ${ }^{27} \mathrm{Al}$ MQMAS NMR spectra of the studied samples at room temperature. 


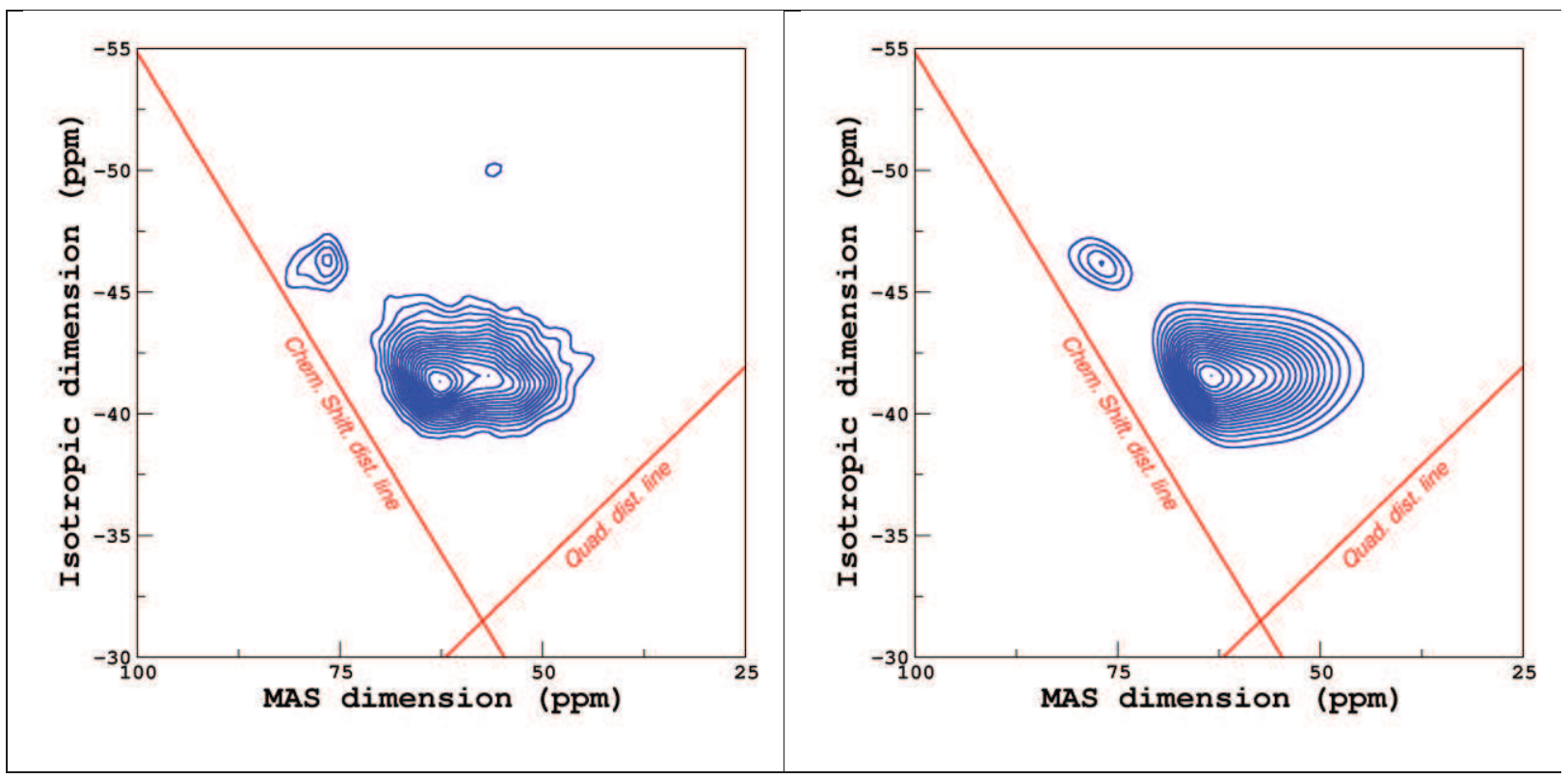

Fig. S6: Experimental (left) and simulated (right) ${ }^{27}$ Al MQMAS spectra of S2. 